BENHA VETERINARY MEDICAL JOURNAL, VoL. 36, No. 2:367-372, JUNE, 2019

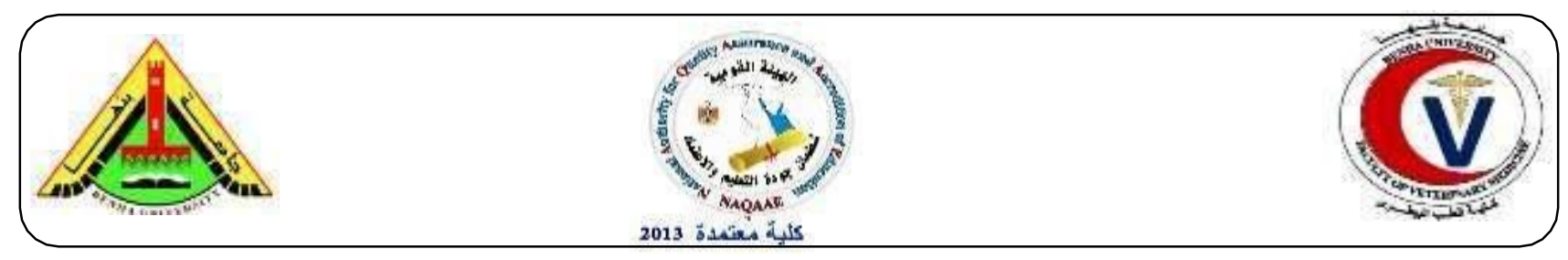

\title{
Effects of commercial pellet and mash feed on performance of broiler chickens
}

\author{
Nasser E. Khdr, Tahya E. Ismael and Fatma S. Mohamed \\ Nutrition and Clinical Nutrition Department, Faculty of Veterinary Medicine, Benha University
}

\section{A B STRACT}

The study determined the effects of feeding different feed forms on growth performance and economic efficiency of cobb broiler chickens. Different feed forms used are pellets and mash feed. A total of 43855 broiler chicks of the Cobb were used in a completely randomized design with two different forms of diets with three replicates for each group. The broiler chickens were raised for five weeks. Live body weight (BW), weight gain (WG), feed intake (FI) and feed conversion ratio (FCR) were measured weekly from the first week to fifth week. Economic efficiency was recorded at the end of trial at (day 35). It can be concluded that similarities in feed conversion and improvement in growth response for pellet-fed birds than those of mash fed birds. The results showed that the production index was the highest in broilers fed pellet than mash diets. The economic efficiency was higher $(\mathrm{P}<0.05)$ in broiler fed mash than pellet diets.

Key words: Broiler chicks; growth performance; Mash; Pellets.

Abbreviation: BW, body weight; WG, weight gain; FI, feed intake; FCR, feed conversion ratio; SDS, sudden death syndrome; $M E$, metabolizable energy; $C P$, crude protein; EE, ether extract; $C F$, crude fiber.

(http://www.bvmj.bu.edu.eg) (BVMJ-36(2): 378-383, 2019)

\section{INTRODUCTION}

The cost of feed is a primary concern to the poultry industry since it compromises about 60 $70 \%$ of the total cost of broiler production.

Various feed forms including pellet, mash or crumble are supplied to broiler. Ration forms are the most important factors which directly affect the cost of mixed feed and production performance of broiler. Mash is a form of a complete feed that is finely ground and mixed so that birds cannot easily separate out ingredients. Each mouthful provides a well-balanced diet. Mash diet gives greater unification of growth and less death loss and is more economical. However, ground feed is not so palatable and does not retain its nutritive value as well as ungrounded feed. Pellet system of feeding is really a modification of the mash system by mechanically pressing the mash into hardy pellets or "artificial grains". It is generally accepted that, compared to mash, the feeding of pellets improves feed conversion. The greatest advantage in using pellets is that there is little waste in feeding. The disadvantage is that pellets are expensive-about 10 percent more expensive than that of feeds not pelleted. (proudfoot and Hulan, 1982)observed that the incidence of sudden death syndrome (SDS) was significantly higher for broilers fed on crumblepellet or ground crumble-pellet form diet than for birds fed on mash. There are several advantages of feeding poultry with pellets rather than mash. Pelleting reduces waste of chicken feed, water soiling, and selective eating behavior in chickens , reduces bulkiness of feed by $15-18 \%$, reduces Salmonella, E. coli, molds and more, and 
destroys growth inhibitors, like trypsin inhibitors and gossypol during processing The pelleting process solves mixing difficulties, incorrect particle sizes, and ingredient separation results in the saving of $15-20 \%$ of broiler chicken .feed cost produces a higher nutrient density, increases the availability of Vitamin E and B12, and improves digestibility and ME value of certain ingredients, thereby increasing animal performance while creating superior feed efficiency. The aim of the present study was to investigate the effect of pellet and mash diets on the broiler chicks' performance.

\section{MATERIALS AND METHODS}

\subsection{Birds, housing and management}

A total of 43855 broiler chicks of the Cobb strain obtained from a commercial source were reared conventionally in floor pens. For acclimatization, the chicks were started on a control starter diet for a period of 12 days. The birds were distributed at random into two groups, mash group about 22050 and pellet group about 21805 assigned to two experimental dietary treatments. Food and water were provided on ad libitum basis and continuous lighting was used. Birds were weighed at the beginning of the experiment and then weekly for five weeks later after a $12 \mathrm{~h}$ (over- night) fast, the daily feed intake and daily gain for each group was recorded.

\subsection{Diets}

The basal diet (Table 1) was formulated from corn, soybean meal, full fat soybean, Corn gluten meal, dicalcium phosphate, limestone, vitamin and mineral premix, soybean oil while the deficient nutrients were supplemented using DLmethionine, lysine, L-threonine, dicalcium phosphate, soybean oil ,enzymes , ant mycotoxin, and anticoccidia and ant clostridia shown in table (1).

\subsection{Experimental procedure:}

2.3.1. Chicks

Chicks had free access to feed and water and were vaccinated according to the sanitary programs for this category and coccidiostats was applied at the prophylactic dose.

2.3.2. Feed consumption

Feed consumption was recorded for each treatment. Live body weight in grams was measured for all birds at the beginning of the experiment and was weekly repeated at the same time.

\subsubsection{Daily mortality}

Mortality rate was recorded for each treatment and the weekly mortality rate was calculated by subtracting the number of dead chicks from the number of live chicks

\subsection{Financial cost}

As broiler industry is based on momentary returns rather than maximal chick performance, the main purpose of this item is to investigate the economical possibility of using mash or pellet feed in broiler chick diets. According to guidelines of economic evaluation, the production costs include chick price, feed cost, management care, and final body weight. The economic efficiency of the present study could be calculated from input-output analysis based mainly upon the total feeding cost and the prevailing selling price of live body weight.

\subsection{Statistical analysis}

The data were subjected to ANOVA and t-test procedures. Statements of statistical significance were based on $\mathrm{P}<0.05$ according to Kaleida Graph TM computer program (2000). 
Table (1): Ingredient composition and nutrient content of experiment diets.

\begin{tabular}{|c|c|c|c|c|c|c|}
\hline \multirow[t]{2}{*}{ Items } & \multicolumn{2}{|c|}{ Starter } & \multicolumn{2}{|c|}{ Grower } & \multicolumn{2}{|c|}{ Finisher } \\
\hline & Mash & Pellet & Mash & Pellet & Mash & Pellet \\
\hline Yellow corn & 551 & 560.34 & 571.75 & 597.20 & 616.95 & 650 \\
\hline Soybean meal(46) & 350.00 & 306 & 317 & 227 & 268 & 169 \\
\hline Corn gluten meal & 6 & 35 & - & 28 & - & 30 \\
\hline Sunflower meal 36\%CP & 25 & & 25 & & 30 & \\
\hline Full fat soybean meal & - & 51 & - & 103 & - & 110 \\
\hline Soy oil & 21 & - & 35 & - & 45 & - \\
\hline DL-methionine & 2.850 & 3.2 & 2.6 & 2.9 & 2.55 & 2.350 \\
\hline L-Lysine & 2.15 & 2.8 & 1.35 & 2.7 & 1.5 & 2.550 \\
\hline L-Threonine & 0.250 & 0.5 & 9.2 & 0.8 & 0.6 & 0.500 \\
\hline Sodium chloride & 2.8 & 2.75 & 2.65 & 2.55 & 2.65 & 2.55 \\
\hline Sodium bicarbonate & 2.2 & - & 2.1 & - & 2.1 & - \\
\hline Sodium sulphate & - & 2 & - & 2 & - & 2.1 \\
\hline Dicalcium phosphate & 17.400 & 16.65 & 15 & 13.75 & 14 & 13 \\
\hline Limestone. & 14 & 14.5 & 13 & 14.65 & 11.250 & 12.500 \\
\hline Vit, Min mixture with enzymes & 3 & 3 & 3 & 3 & 3 & 3 \\
\hline Emulsifier & 0.150 & 0.1 & 0.15 & 0.25 & 0.2 & 0.25 \\
\hline Protease enzyme & 0.100 & 0.06 & 0.1 & 0.1 & 0.1 & 0.1 \\
\hline Choline chloride & 0.5 & 0.5 & 0.5 & 0.5 & 0.5 & 0.5 \\
\hline Ant coccidian & 0.5 & 0.5 & 0.5 & 0.5 & 0.5 & 0.5 \\
\hline Ant mycotoxin & 0.5 & 0.5 & 0.5 & 0.5 & 0.5 & 0.5 \\
\hline Ant clostridia & 0.5 & 0.5 & 0.5 & 0.5 & 0.5 & 0.5 \\
\hline Antioxidants & 0.1 & 0.1 & 0.1 & 0.1 & 0.1 & 0.1 \\
\hline Total (Kg) & 1000 & 1000 & 1000 & 1000 & 1000 & 1000 \\
\hline \multicolumn{7}{|l|}{ Chemical analysis } \\
\hline ME (kcal/kg) & 3060 & 3000 & 3192 & 3150 & 3260 & 3217 \\
\hline $\mathrm{CP} \%$ & 22.5 & 22.710 & 21.00 & 21 & 19 & 19 \\
\hline $\mathrm{CF} \%$ & 2.79 & 2.450 & 2.740 & 2.560 & 2.770 & 2.530 \\
\hline $\mathrm{EE} \%$ & 4.55 & 3.500 & 5.970 & 4.500 & 7.040 & 4.760 \\
\hline Lysine $\%$ & 1.35 & 1.360 & 1.20 & 1.270 & 1.090 & 1.130 \\
\hline Methionine+Cystine\% & 1.02 & 1.040 & 0.95 & 1.010 & 0.900 & 0.920 \\
\hline Threonine $\%$ & 0.92 & 0.920 & 0.860 & 0.920 & 0.820 & 0.820 \\
\hline Total calcium $\%$ & 1.05 & 1.03 & 0.95 & 0.960 & 0.840 & 0.86 \\
\hline Available phosphorus\% & 0.5 & 0.5 & 0.45 & 0.45 & 0.4200 & 0.42 \\
\hline Sodium $\%$ & 0.18 & 0.18 & 0.17 & 0.17 & 0.17 & 0.17 \\
\hline Chloride\% & 0.23 & 0.23 & 0.22 & 0.22 & 0.22 & 0.22 \\
\hline Potassium\% & 0.890 & 0.860 & 0.830 & 0.790 & 0.750 & 0.700 \\
\hline $\mathrm{DEB}(\mathrm{MEQ} / \mathrm{KG})$ & 246.950 & 221.060 & 230.780 & 183.790 & 209.140 & 160.020 \\
\hline
\end{tabular}

\section{RESULTS AND DISCUSSION}

\subsection{Growth performance}

Different growth performance parameters, weight changes, average weekly body weight, body weight gain, feed intake, feed conversion ratio were presented in the Table $2-5$. At the same time week wise table of the above-mentioned parameters also presented and discussed subsequently.

Feed Intake was not significantly $(\mathrm{P}>0.05)$ affected by physical type of feed but significant at $(\mathrm{P} \leq 0.05)$ in 3rd week only. However, Broilers fed pellet diet had numerically increased feed intake compared with birds fed mash diet since Birds preferentially consume larger feed particles. This agreed with Cutlip, S. E., et al 
(2003) and Moritz, et al (2008) who found that feed intake, weight gain, and final body weight increased. According to Klasing (2000), poultry prefer to eat particles with an oval shape as they are easier to grasp, and therefore less time is required to feed. Hence, feed intake regulation depends on diet physical form, as poultry prefer large particles instead of finely ground meals (Moran, 1987). The weight gain was significantly greater in broilers fed pellet diets than mash diets when assessed over trial period. Fairfield (2003) noticed that pelleting of feed also provides the benefits of increasing the bulk density of feed, improving feed flow ability.

Table (2): The effect of different feed forms (pellet and mash) on feed intake (g) of broiler chicks.

\begin{tabular}{ccc}
\hline Feed consumption / week & Pellet feed & Mash feed \\
\hline First week & $229.35 \pm 8.66$ & $210.50 \pm 5.77$ \\
Second week & $357.80 \pm 5.77$ & $351.10 \pm 8.66$ \\
Third week & $653.66^{\mathrm{a}} \pm 11.55$ & $578.30^{\mathrm{b}} \pm 2.89$ \\
Fourth week & $841.71 \pm 2.89$ & $863.60 \pm 11.55$ \\
Fifth week & $1041.30 \pm 3.46$ & $1035.10 \pm 8.66$ \\
Total feed & $3123.80 \pm 26.56$ & $3038.60 \pm 37.53$
\end{tabular}

- Values are means \pm standard errors

- Means with different letters at the same column differ significantly at $(\mathrm{P} \leq .05)$.

Table (3): The effect of different feed forms (pellet and mash) on live body weigh changes in gram / broiler chick.

\begin{tabular}{ccc}
\hline Body weight /week & Pellet feed & Mash feed \\
\hline Initial weight & $40.00 \mathrm{a} \pm 2.89$ & $42.00 \mathrm{a} \pm 5.77$ \\
First week & $179.03^{\mathrm{a}} \pm 0.93$ & $171.60^{\mathrm{b}} \pm 0.29$ \\
Second week & $439.67^{\mathrm{a}} \pm 4.62$ & $426.42^{\mathrm{b}} \pm 1.69$ \\
Third week & $849.00^{\mathrm{a}} \pm 4.54$ & $791.50^{\mathrm{b}} \pm 1.76$ \\
Fourth week & $1415.00^{\mathrm{a}} \pm 7.75$ & $1371.70^{\mathrm{b}} \pm 4.92$ \\
Fifth week & $2000.50^{\mathrm{a}} \pm 14.68$ & $1983.50^{\mathrm{a}} \pm 13.89$ \\
\hline
\end{tabular}

- Values are means \pm standard errors

- Means with different letters at the same column differ significantly at $(\mathrm{P} \leq .05)$.

Fig. (1): The effect of different feed forms (pellet and mash) on body weight

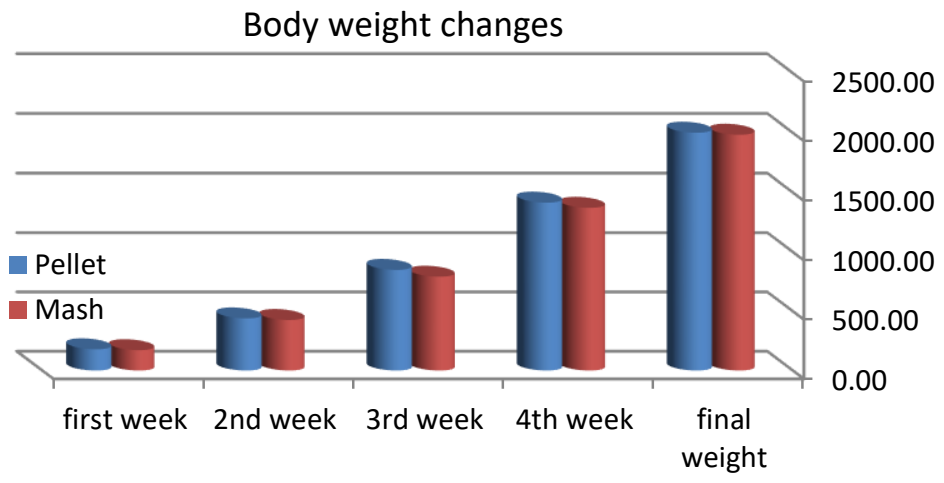


Table (4): the effect of different feed forms (pellet and mash) on body weight gain (g) of broiler chicks

\begin{tabular}{ccc}
\hline Period / weeks & Pellet feed & Mash feed \\
\hline $0-1$ & $139.03^{\mathrm{a}} \pm 2.42$ & $129.60^{\mathrm{a}} \pm 5.63$ \\
$1-2$ & $260.63^{\mathrm{a}} \pm 4.40$ & $254.82^{\mathrm{a}} \pm 1.61$ \\
$2-3$ & $409.33^{\mathrm{a}} \pm 9.14$ & $365.08^{\mathrm{b}} \pm 3.18$ \\
$3-4$ & $566.00^{\mathrm{a}} \pm 8.19$ & $580.17^{\mathrm{a}} \pm 4.51$ \\
$4-5$ & $585.50^{\mathrm{a}} \pm 16.58$ & $611.83^{\mathrm{a}} \pm 15.20$ \\
$0-5$ & $1960.50^{\mathrm{a}} \pm 17.02$ & $1941.50^{\mathrm{a}} \pm 17.21$ \\
\hline
\end{tabular}

- Values are means \pm standard errors

- Means with different letters at the same column differ significantly at $(\mathrm{P} \leq .05)$.

3.2. Feed conversion ratio (FCR):

Feed conversion ratio: Feed conversion ratio during the whole experimental period was not significant (Table 5).

Table (5): the effect of different feed forms (pellet and mash) on feed conversion ratio of broiler chicks.

\begin{tabular}{ccc}
\hline Feed conversion/week & Pellet feed & Mash feed \\
\hline $0-1$ & $1.65 \pm 0.09$ & $1.63 \pm 0.12$ \\
$1-2$ & $1.37 \pm 0.04$ & $1.38 \pm 0.03$ \\
$2-3$ & $1.60 \pm 0.03$ & $1.58 \pm 0.02$ \\
$3-4$ & $1.49 \pm 0.02$ & $1.49 \pm 0.03$ \\
$4-5$ & $1.78 \pm 0.05$ & $1.69 \pm 0.05$ \\
$0-5$ & $1.59 \pm 0.03$ & $1.57 \pm 0.03$ \\
\hline
\end{tabular}

- Values are means \pm standard errors

-Means within the same column are non-significant at $(\mathrm{P}>0.05)$.

3.3. Survival rate, production index and the highest in broilers pellet than mash diets. The economic efficiency:

economic efficiency was higher $(\mathrm{P}<0.05)$ in

The data concerning economic efficiency are

broiler fed mash than pellet diets

Table (6): the effect of different feed forms (pellet and mash) on economic efficiency

\begin{tabular}{lcc}
\hline \multicolumn{1}{c}{ Items } & Pellet feed & Mash feed \\
\hline Total feed cost & $20.78^{\mathrm{a}} \pm 0.18$ & $18.69^{\mathrm{b}} \pm 0.23$ \\
Veterinary management cost & 4.00 & 4.00 \\
Rent & 1.00 & 1.00 \\
Equipment & 0.30 & 0.30 \\
Labor & 0.50 & 0.50 \\
Chick price & 4.00 & 4.00 \\
Water and electricity & 0.25 & 0.25 \\
Total cost & $30.83^{\mathrm{a}} \pm 0.18$ & $28.74^{\mathrm{b}} \pm 0.23$ \\
Return & $40.01 \pm 0.29$ & $39.67 \pm 0.28$ \\
Net profit & $9.18^{\mathrm{b}} \pm 0.45$ & $10.93^{\mathrm{a}} \pm 0.43$ \\
Production index & 311 & 296.8 \\
\hline - Values are means \pm standard errors & \multicolumn{2}{|}{} \\
- Means within the same column carrying different superscripts are significant at $(\mathrm{P} \leq 0.05)$.
\end{tabular}




\section{CONCLUSION}

From the previous results, it can be concluded that similarities in feed conversion and improvement in growth response for pellet-fed birds. The production index was the highest in broilers pellet than mash diets. The economic efficiency was higher $(\mathrm{P}<0.05)$ in broiler fed mash than pellet diets.

\section{REFERENCES}

Cutlip, S. E., Hott, J. M., Buchanan, N. P., Rack, A. L., Latshaw, J. D. and Moritz, J. S. 2008. The Effect of Steam-Conditioning Practices on Pellet Quality and Growing Broiler Nutritional Value. J. Appl. Poult. Res. 17:249-261.

Moritz, J. S., Cramer, K. R., Wilson, K. J. and Beyer, R. S. 2003. Feed manufacture and feeding of rations with graded levels of added moisture formulated to different energy densities. J. Appl. Poult. Res. 12:371-381.

Kaleida Graph TM computer program 2000. Data Analysis and Graphic Presentation for Business, Science and Engineering. Version 35b5 March 22.

Klasing KC. 2000. Comparative avian nutrition. New York: CABI Publishing; .

Moran ET. 1987. Pelleting: affects feed and its consumption. Poultry Science ;5(1):3037.

Proudfoot F.G H.W. Hulan, 1982. Poult. Sci., 61: 750-754.

D. A. Fairfield, 2003."Pelleting for profit—part 1," National Grain and Feed Association. Feed and Feeding Digest, vol. 54, no. 6,pp. 1-5. 